\title{
CORRELATION OF ASPHALTENE SOLVATION WITH STABILITY OF CRUDE OIL EMULSION USING SCALING EQUATIONS
}

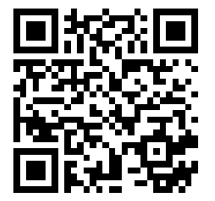

Emmanuel J. Ekott ${ }^{*}{ }^{\circledR}$

${ }^{1}$ Department of Chemical Sciences, Heritage Polytechnic, Eket, Nigeria

DOI: https://doi.org/10.29121/IJOEST.v4.i3.2020.87

Article Type: Research Article

Article Citation: Emmanuel J. Ekott. (2020). CORRELATION OF ASPHALTENE SOLVATION WITH STABILITY OF CRUDE OIL EMULSION USING SCALING EQUATIONS. International Journal of Engineering Science

Technologies, 4(3), 19-29. https://doi.org/10.29121/IJOEST.v 4.i3.2020.87

Received Date: 10 May 2020

Accepted Date: 29 May 2020

Keywords:

Crude Oil

Emulsion

Asphaltene

Solvation

Bancroft's rule

Scaling Equations

\section{ABSTRACT}

Due to the simplicity of scaling equations and its applicability to colloid chemistry, the scaling theory is widely used in studying emulsion properties such as force profiles. Scaling equations were developed for the studied samples for correlation of asphaltene solvation with stability of crude oil emulsions. Correlations were made for viscosity and percentage water resolved by varying the volume concentration of toluene in heptol mixture that was used as solvent for the asphaltene re-dissolution. The study shows that tuning the composition of heptol allows fine control of colloidal forces between asphaltene surfaces in an organic solvent and therefore determines the stability state of the emulsion. Statistically derived correlation equations provide for a range in the aromaticity of the crude medium for which an optimum stability is observed and therefore gives good understanding on the control of emulsion stability. The study further shows that emulsion inversion can be achieved by adjusting the concentration of surfactant.

\section{INTRODUCTION}

Crude oil is a complex fluid containing asphaltenes, resins and napthenic acid in addition to saturates and aromatic hydrocarbons. Asphaltenes is the heaviest and most polar fraction in the crude oil and stabilized the water in oil emulsion that occurred during crude oil production. Problems associated with oil well production, pipeline transfer, land and sea-based transportation and ultimately, oil refining have been heavily linked to the presence of asphaltenic colloids in the crude oil. This can increase pumping and transportation expenses, corrosion of pipes, pumps, production equipment and distillation columns, and the poisoning of downstream refinery catalysts. During visbreaking and catalytic hydrocracking large amounts of sludge and sediment can form ostensibly due to the flocculation of asphaltenes during processing. Coke generation and asphaltene adsorption within catalytic cracking beds can reduce the effective catalyst surface area as well as the efficiency of coal hydropyrolysis (Specker and Kilpatrick, 2004). Asphaltene deposition within reservoir rocks has been blamed for pronounced reductions in well

(C) 2020 The Author(s). This is an open access article distributed under the terms of the Creative Commons Attribution License, which permits unrestricted use, distribution, and reproduction in any medium, provided the original author and source are credited. 
productivity (Cimino et al, 1995). According to Siffert, Bourgeois and Papirer (1984) asphaltenes have been found to facilitate the formation of extremely stable water-in-crude oil emulsions. Understanding asphaltene chemistry and the fundamental mechanisms of colloid formation has been the driving force behind much petroleum research in recent years. The study of asphaltene colloidal properties has been motivated by their propensity to aggregate, flocculate, precipitate, and to adsorb onto interfaces (Espinat et al, 1993). To help improve the conversion of crude oil into useful products by reducing losses to sludge and emulsions, it is necessary to better understand the factors that affect their formation. Paramount to this understanding is an in-depth knowledge of the structures and interactions of the asphaltenic components responsible. Ekott and Akpabio (2013) investigated asphaltene solvation nexus and stability analyses of heavy crude oil emulsions and reported that tuning the composition of heptol allows fine control of colloidal forces between asphaltene surfaces in an organic solvent and therefore determines the stability state of the emulsion. Their study revealed that the crude aromaticity is definitely a primary factor in determining the stability of asphaltene-stabilized emulsions while the asphaltene type plays at least a secondary role in determining the resultant emulsion stability. Their recommendation of extending the study range to toluene volume fraction of 0.9 necessitated this study. This study correlates asphaltene solvation with stability of water in crude oil emulsion using scaling equations.

Third order polynomial curve fitting equations have been reported by Hong and Watkinson (2004) to best fit the solubility of asphaltene. They however reported that the solubility of asphaltenes from different crude source conform to different scaling equation. Hu et al (2004) elaborated on scaling equations and stated that polynomial curve fitting equations of third order fit the modeling of asphaltene precipitation. This has been collaborated by Wang (2011) where third order polynomial curve fitting equations were used as scaling equations for measurement of asphaltene colloidal force. Wang (2011) stated that due to the simplicity of scaling equations and its applicability to colloid chemistry, the scaling theory is widely used in studying emulsion properties such as force profiles.

\section{MATERIALS AND METHODS}

Using asphaltene solvation test results as reported by Ekott and Akpabio (2013), scaling equations were developed for the studied samples for correlation of asphaltene solvation with stability of crude oil emulsions for solvation range outside the laboratory studied range. The researcher used five crude oil emulsion samples from Niger Delta region of Nigeria for their study. Samples were collected from both onshore and offshore oil well sources for balanced investigation. The onshore samples were SPDC Yokri, SPDC Otumara, and Seplat Oben emulsions. Chevron VRMT and Mobil QIT emulsions were from offshore locations. The samples were collected into labelled plastic containers from flow stations by opening of the respective flow valves. $100 \mathrm{ml}$ of crude oil emulsion sample was measured and weighed. $25 \mathrm{ml}$ of $\mathrm{n}$-heptane was added, and shaken to dissolve for 10 minutes. It was then vacuum filtered. The precipitate was rinsed with excess n-heptane until the effluent runs were clear. The precipitate was then dried in an oven at $25 \mathrm{oC}$ for an hour. $3 \mathrm{~g}$ portion each was measured into 5 different flasks and $1 \mathrm{ml}$ each of 5 different heptol mixtures was added. The heptol mixtures were prepared by mixing heptane and toluene in the following proportion by volume respectively: 90:10, 80:20, 70:30, 60:40, and 50:50. To each flask, a fresh crude oil emulsion sample was added to make a volume $300 \mathrm{ml}$ (this was the viscometer required volume for measurement of viscosity). It was stirred and allowed to stand for 1 hour. The viscosity of each of the mixtures was then measured with viscometer and recorded after thorough stirring. $10 \mathrm{ml}$ of each of the mixtures was thereafter taken into 5 test tubes and $1 \mathrm{ml}$ of QIT 007 demulsifier was added to each test tube and allowed to stand for 10 minutes. The percentage water separated was recorded as an index for stability of emulsion based on the contribution of soluble asphaltene. The entire process was repeated for the other four crude oil emulsion samples.

\section{RESULTS AND DISCUSSION}

Experimental results obtain for the work were published by Ekott and Akpabio (2013) and presented here on table 1. 
Table 1: Viscosities (CST) and Percentage Water Separation for Asphaltene Solvation Tests

\begin{tabular}{|c|c|c|c|c|c|c|c|c|c|c|}
\hline \multirow{2}{*}{ 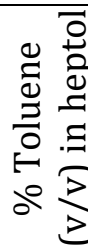 } & \multicolumn{2}{|c|}{ SPDC Yokri } & \multicolumn{2}{|c|}{ SPDC Otumara } & \multicolumn{2}{|c|}{ Chevron VRMT } & \multicolumn{2}{|c|}{ Seplat-Oben } & \multicolumn{2}{|c|}{ Mobil QIT } \\
\hline & 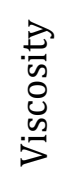 & 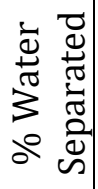 & 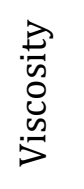 & 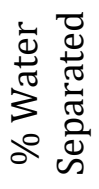 & 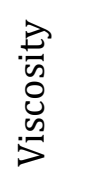 & 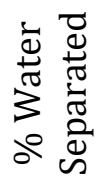 & $\begin{array}{l}\vec{D} \\
\stackrel{\vec{n}}{0} \\
\dot{n} \\
\vdots\end{array}$ & 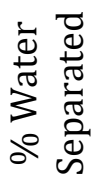 & 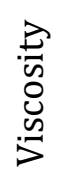 & 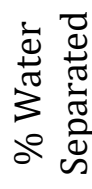 \\
\hline 0.1 & 40 & 35 & 41 & 20 & 39 & 26 & 27 & 50 & 10 & 6 \\
\hline 0.2 & 41 & 25 & 45 & 16 & 40 & 18 & 32 & 40 & 10 & 4 \\
\hline 0.3 & 44 & 20 & 49 & 12 & 43 & 10 & 34 & 25 & 12 & 4 \\
\hline 0.4 & 46 & 15 & 53 & 10 & 46 & 6 & 38 & 20 & 12 & 3 \\
\hline 0.5 & 50 & 8 & 55 & 6 & 48 & 4 & 40 & 10 & 13 & 2 \\
\hline
\end{tabular}

Using observed data for each of the studied samples (table 1), scaling equations were developed. The general form of a polynomial of order $j$ curve fitting equation is presented in equation 1

$f(x)=a_{0}+a_{1} x+a_{2} x^{2}+a_{3} x^{3}+\cdots+a_{j} x^{j}=a_{0}+\sum_{k=1}^{j} a_{k} x^{k}$

Equation 1

The expression for any error using the least squares approach is given by equation 2

err $=\sum\left(d_{i}\right)^{2}=\left(y_{1}-f\left(x_{1}\right)\right)^{2}+\left(y_{2}-f\left(x_{2}\right)\right)^{2}+\left(y_{3}-f\left(x_{3}\right)\right)^{2}+\left(y_{4}-f\left(x_{4}\right)\right)^{2}$

Equation 2

The intention is to minimize this error. Substituting equation 1 into equation 2, equation 3 is obtained thus:

$e r r=\sum_{i=1}^{n}\left(y_{i}-\left(a_{0}+a_{1} x+a_{2} x^{2}+a_{3} x^{3}+\cdots+a_{j} x^{j}\right)\right)^{2}$

Equation 3

Where $\mathrm{n}=$ number of observed data points, $\mathrm{i}=$ the current data point being summed and $\mathrm{j}=$ the polynomial order. Equation 3 can be re-written as:

err $=\sum_{i=1}^{n}\left(y_{i}-\left(a_{0}+\sum_{k=1}^{j} a_{k} x^{k}\right)\right)^{2}$

Equation 4

To minimize equation 4 , find the coefficients $a_{0}, a_{k}$ by first taking derivative with respect to each coefficient $a_{0}, a_{k}$ where $\mathrm{k}=1, \ldots$, and $\mathrm{j}=0$.

$$
\begin{aligned}
& \frac{\partial e r r}{\partial a_{0}}=-2 \sum_{i=1}^{n}\left(y_{i}-\left(a_{0}+\sum_{k=1}^{j} a_{k} x^{k}\right)\right)=0 \\
& \frac{\partial e r r}{\partial a_{1}}=-2 \sum_{i=1}^{n}\left(y_{i}-\left(a_{0}+\sum_{k=1}^{j} a_{k} x^{k}\right)\right) x=0 \\
& \frac{\partial e r r}{\partial a_{2}}=-2 \sum_{i=1}^{n}\left(y_{t}-\left(a_{0}+\sum_{k=1}^{j} a_{k} x^{k}\right)\right) x^{2}=0 \\
& \frac{\partial e r r}{\partial a_{j}}=-2 \sum_{i=1}^{n}\left(y_{t}-\left(a_{0}+\sum_{k=1}^{j} a_{k} x^{k}\right)\right) x^{j}=0
\end{aligned}
$$

Equation 5 
Rewriting equation 5 and putting into matrix, give equation 6

$$
\left(\begin{array}{llll}
n & \sum x_{i} & \sum x_{i}^{2} & \sum x_{i}^{3} \\
\sum x_{i} & \sum x_{i}^{2} & \sum x_{i}^{3} & \sum x_{i}^{4} \\
\sum x_{i}^{2} & \sum x_{i}^{3} & \sum x_{i}^{4} & \sum x_{i}^{5} \\
\sum x_{i}^{3} & \sum x_{i}^{4} & \sum x_{i}^{5} & \sum x_{i}^{6}
\end{array}\right)\left(\begin{array}{l}
a_{0} \\
a_{1} \\
a_{2} \\
a_{3}
\end{array}\right)=\left(\begin{array}{c}
\sum y_{i} \\
\sum\left(x_{i} y_{i}\right) \\
\sum x_{i}^{2} y_{i} \\
\sum x_{i}^{3} y_{i}
\end{array}\right)
$$

\section{Equation 6}

Rewriting equation 6 for a third order polynomial, gives

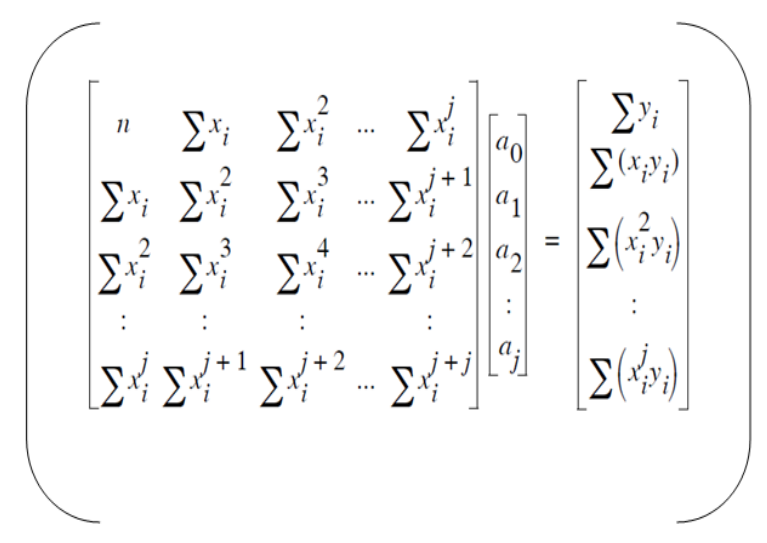

Equation 7

Solving equation 7 for $a_{0}, a_{1}, a_{2}$ and $a_{3}$ provides solution to the third order curve fitting polynomial equation 8

$y=a_{0}+a_{1} x+a_{2} x^{2}+a_{3} x^{3}$

Equation 8

Five third order polynomial equations obtained for viscosity of SPDC Yokri, SPDC Otumara, Chevron VRMT, Seplat-Oben and Mobil QIT emulsions respectively are presented below:

$|y|=39.2+3.5714 x+35.71 x^{2}+2.3283 E-10 x^{3}$

Equation 9

$|y|=38.6+13.8095 x+121.428 x^{2}-166.66 x^{3}$

Equation 10

$|y|=41.2-43.57 x+239.28 x^{2}-250.0 x^{3}$

Equation 11

$|y|=21.2+68.809 x-103.57 x^{2}+83.33 x^{3}$

Equation 12

$|y|=10.4-11.666 x+75.0 x^{2}-83.33 x^{3}$

Equation 13

Similar equations for percentage water resolved were also obtained and presented below for SPDC Yokri, SPDC Otumara, Chevron VRMT, Seplat-Oben and Mobil QIT emulsions respectively.

$|y|=52.6-227.39 x+567.85 x^{2}-583.33 x^{3}$

Equation 14

$|y|=26.8-81.904 x+164.285 x^{2}-166.66 x^{3}$

Equation 15

$|y|=34.8-85.23 x-35.71 x^{2}+166.66 x^{3}$

Equation 16

$|y|=64.0-142.85 x+71.4285 x^{2}+3.2011 E-10 x^{3}$

Equation 17

$|y|=9.8-52.619 x+157.14 x^{2}-166.66 x^{3}$

Equation 18. 
Equations 9 through 13 were used to predict the viscosity of the respective samples at different stages of solvation including extrapolated toluene concentrations of 0.6 to 0.9 volume fractions. Results for the predicted values are presented on table 2 below. Equations 14 through 18 were used to predict the percentage water resolved of the respective samples at different stages of solvation including extrapolated toluene concentrations of 0.6 to 0.9 volume fractions. Absolute values were considered as negative signs only indicated reversal of the plot lines. This was important since viscosity and amount of water resolved cannot be negative. Results for the predicted values are also presented on table 2 below.

Table 2: Predicted Percentage Water Separation and viscosities (cst) of Asphaltene Solvation in heptol using scaling equations

\begin{tabular}{|c|c|c|c|c|c|c|c|c|c|c|}
\hline \multirow{2}{*}{ 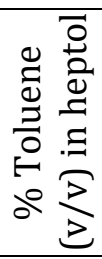 } & \multicolumn{2}{|c|}{ SPDC Yokri } & \multicolumn{2}{|c|}{ SPDC Otumara } & \multicolumn{2}{|c|}{ Chevron VRMT } & \multicolumn{2}{|c|}{ Seplat-Oben } & \multicolumn{2}{|c|}{ Mobil QIT } \\
\hline & $\begin{array}{l}\dot{\Phi} \\
\stackrel{0}{0} \\
3 \\
0\end{array}$ & 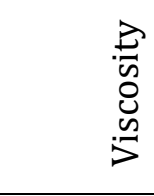 & $\begin{array}{l}\frac{\grave{d}}{\tilde{\pi}} \\
\vdots \\
\vdots \\
0\end{array}$ & 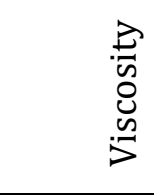 & $\begin{array}{l}\grave{ \pm} \\
\stackrel{ \pm}{0} \\
3 \\
0\end{array}$ & 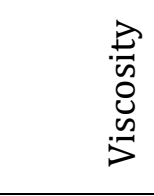 & $\begin{array}{l}\dot{\Phi} \\
\stackrel{\pi}{0} \\
3 \\
0\end{array}$ & 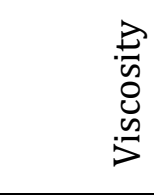 & 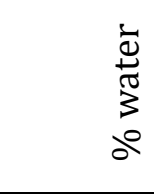 & $\begin{array}{l}\stackrel{\vec{n}}{\tilde{n}} \\
\stackrel{0}{0} \\
\stackrel{0}{>}\end{array}$ \\
\hline 0.1 & 34.9562 & 39.9142 & 20.0858 & 41.0286 & 26.0866 & 38.9858 & 50.4293 & 27.1285 & 5.9428 & 9.9000 \\
\hline 0.2 & 25.1694 & 41.3427 & 15.6573 & 44.8857 & 17.6589 & 40.0572 & 38.2871 & 31.4856 & .2285 & 10.4000 \\
\hline 0.3 & 19.7396 & 43.4853 & 12.5146 & 49.1716 & 10.5169 & 42.9142 & 27.5736 & 34.7713 & 3.6571 & 11.4001 \\
\hline 0.4 & 15.1669 & 46.3422 & 9.6578 & 52.8860 & 5.6606 & 46.0568 & 18.2886 & 37.4855 & 3.2286 & 12.4002 \\
\hline 0.5 & 7.9513 & 49.9132 & 6.0868 & 55.0293 & 4.0900 & 47.9850 & 10.4321 & 40.1283 & 1.9430 & 12.9005 \\
\hline 0.6 & 5.4073 & 54.1984 & 0.8016 & 54.6012 & 6.8050 & 47.1988 & 4.0043 & 43.1995 & 1.1996 & 12.4008 \\
\hline 0.7 & 28.4087 & 59.1979 & 7.1975 & 50.6020 & 14.8055 & 42.1982 & 0.9950 & 47.1992 & 7.1991 & 10.4012 \\
\hline 0.8 & 64.5530 & 64.9115 & 18.9107 & 42.0316 & 29.0915 & 31.4832 & 4.5658 & 52.6274 & 17.0555 & 6.4018 \\
\hline 0.9 & 117.3401 & 71.3394 & 35.3379 & 27.8901 & 50.6630 & 13.5538 & 6.7079 & 59.9840 & 31.7688 & 0.0975 \\
\hline
\end{tabular}

The effect of solvent solvency on viscosity and stability of precipitated asphaltene for each of the samples using scaling equations are presented on figures $1-5$.

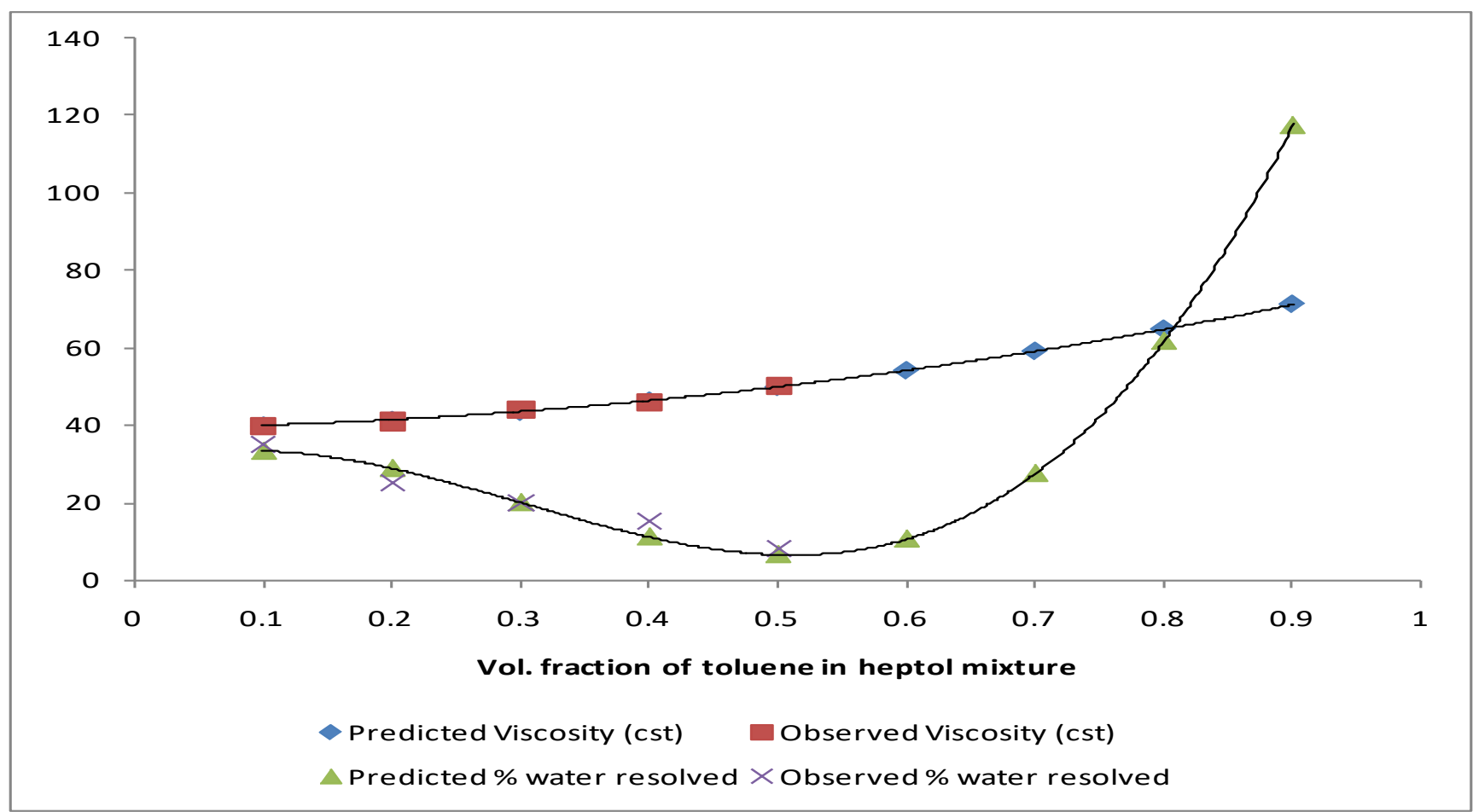

Figure 1: Effect of solvent solvency on viscosity and stability of Precipitated Asphaltene SPDC Yokri Crude Emulsion using scaling equations 
Correlation of Asphaltene Solvation with Stability of Crude Oil Emulsion Using Scaling Equations

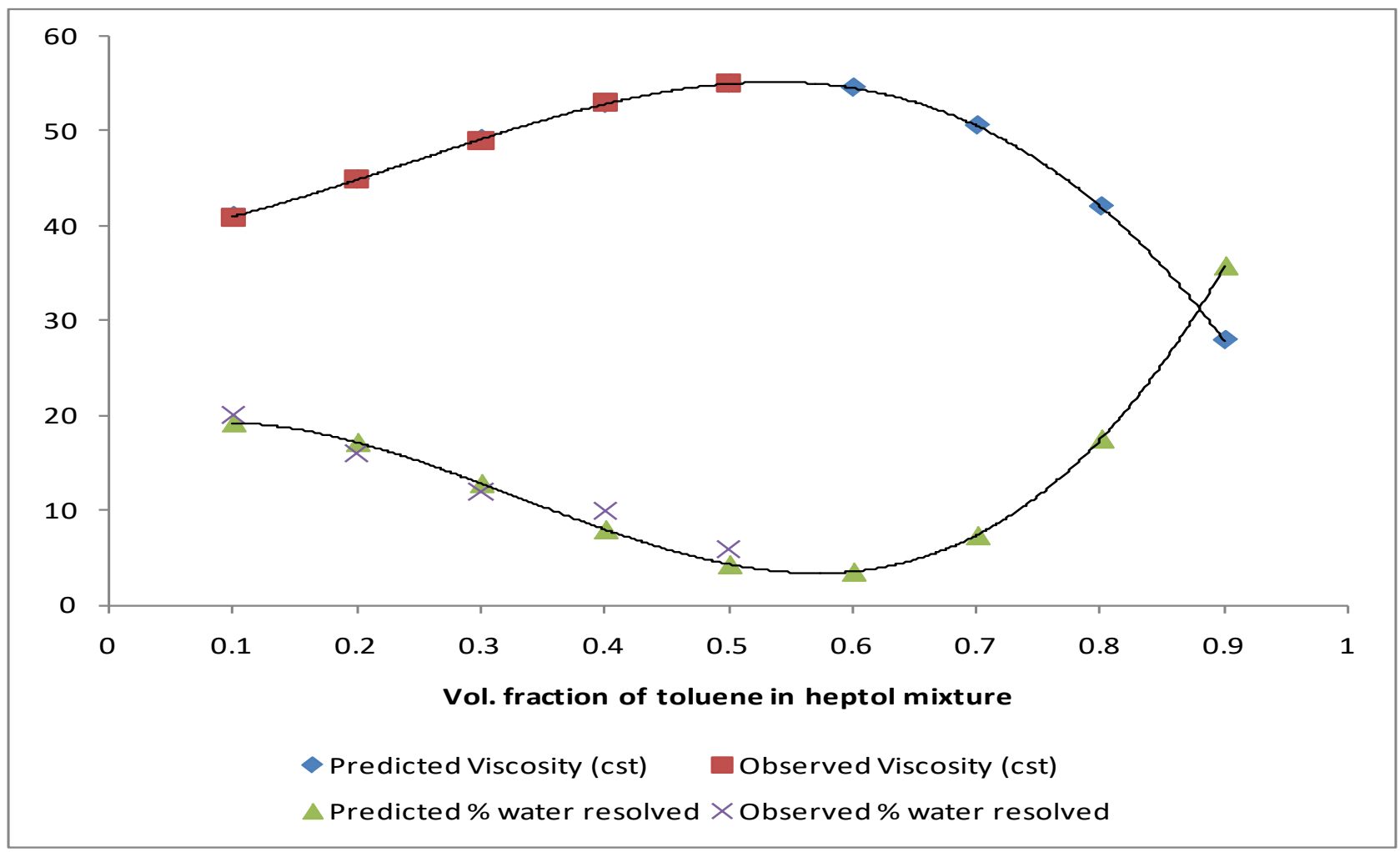

Figure 2: Effect of solvent solvency on viscosity and stability of Precipitated Asphaltene SPDC Otumara Crude Emulsion using scaling equations

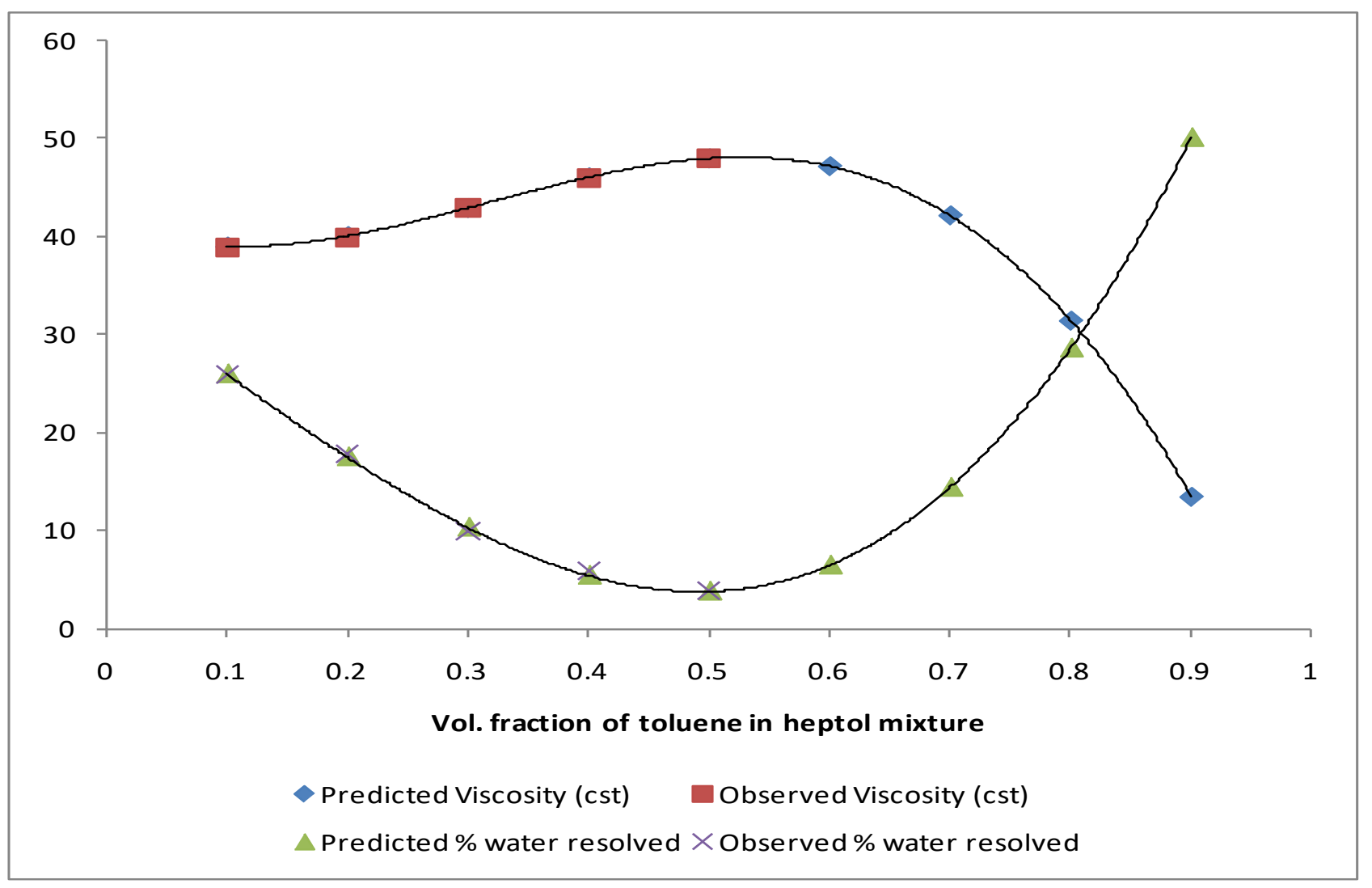

Figure 3: Effect of solvent solvency on viscosity and stability of Precipitated Asphaltene Chevron VRMT Crude Emulsion using scaling equations 
Emmanuel J. Ekott

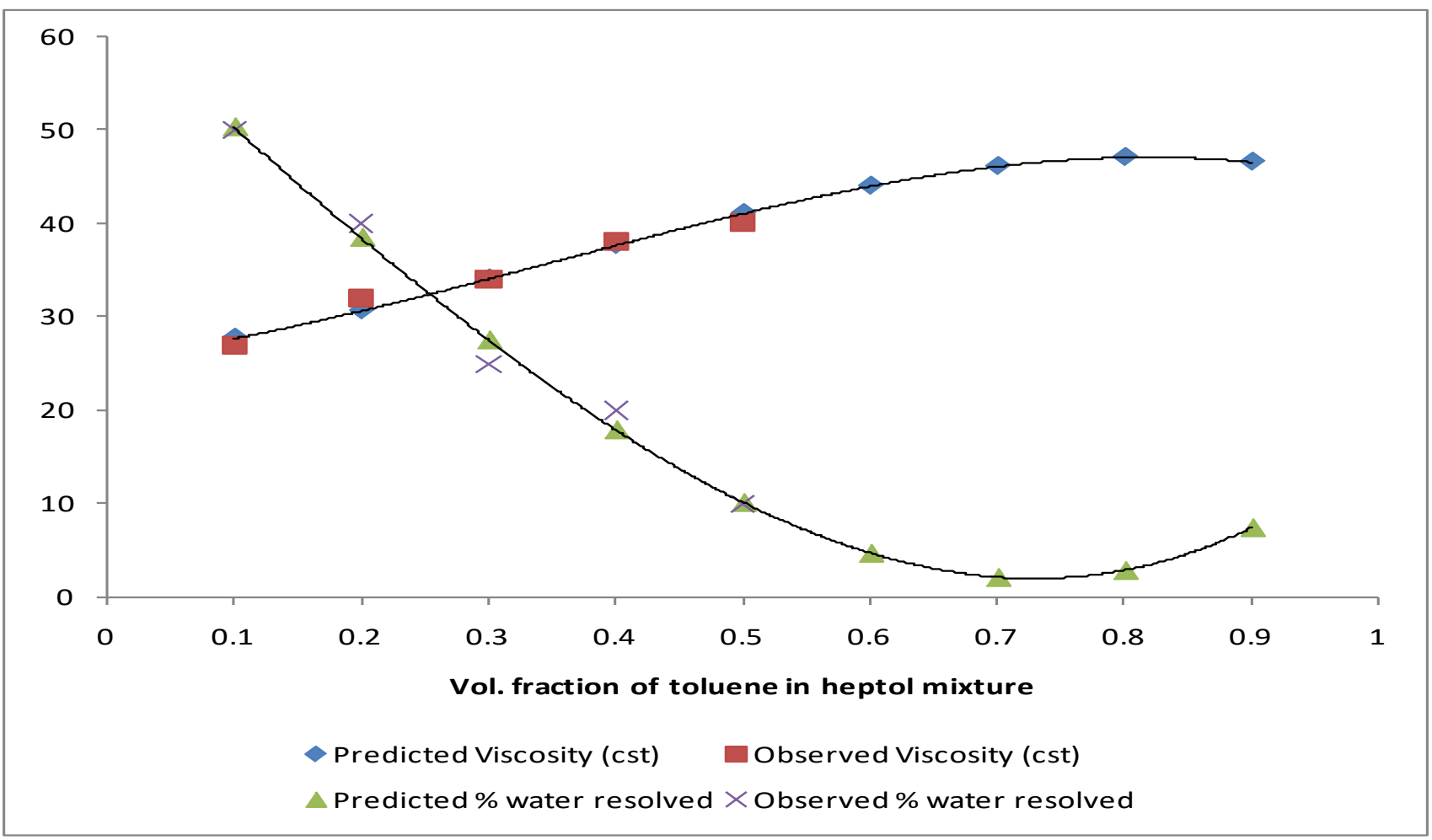

Figure 4: Effect of solvent solvency on viscosity and stability of Precipitated Asphaltene Seplat-Oben Crude Emulsion using scaling equations

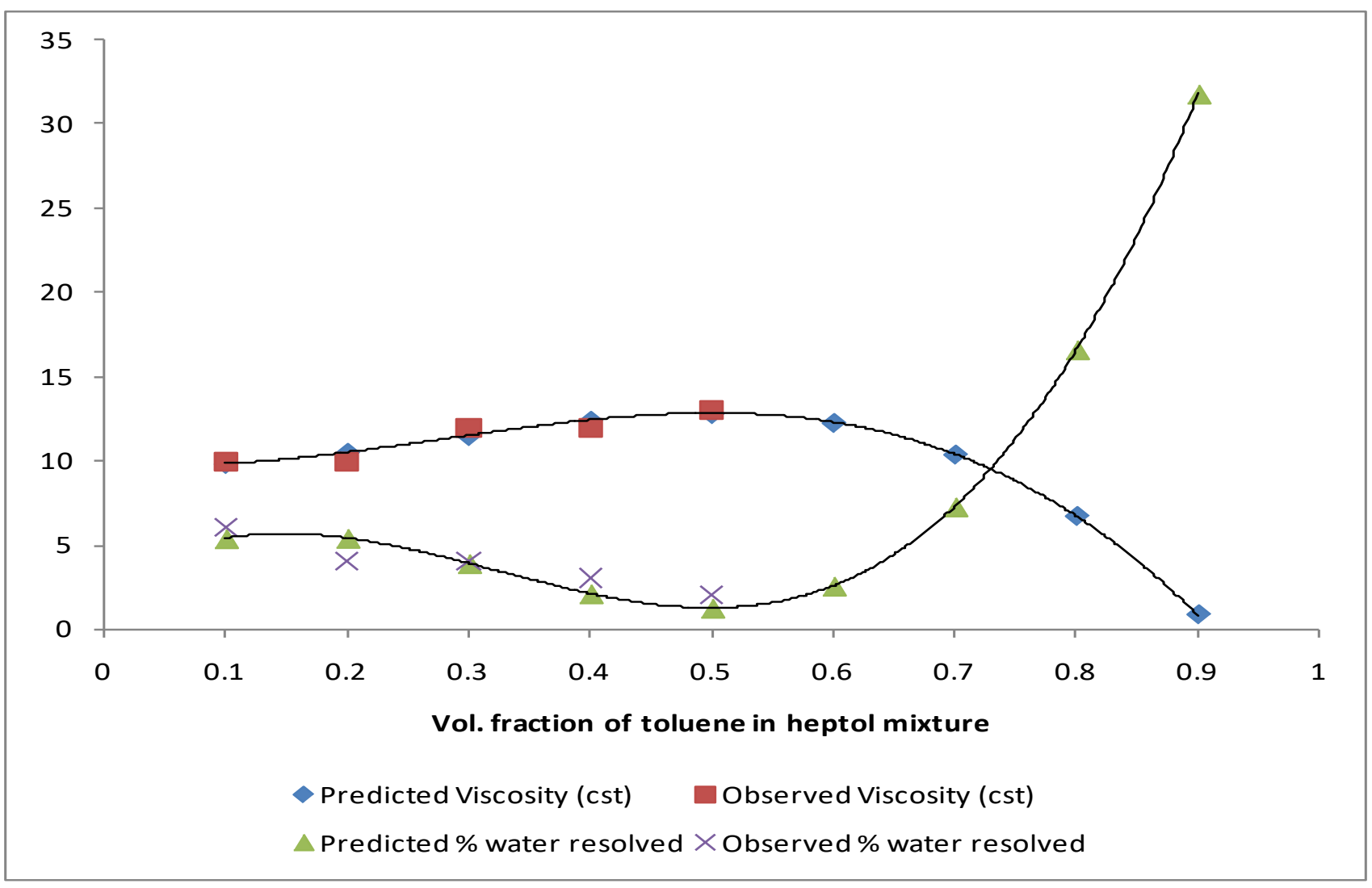

Figure 5: Effect of solvent solvency on viscosity and stability of Precipitated Asphaltene Mobil QIT Crude Emulsion using scaling equations 
These results can be understood in the light of the solubility state of the asphaltenes. McLean and Kilpatrick (1997) established that asphaltenes from Arabian and Venezuelan crude oils were in true solution when the toluene concentration in heptol was greater than $50 \%(\mathrm{v} / \mathrm{v})$ using photon correlation spectroscopy (PCS). When the toluene concentration was reduced from $50 \%$ to $10 \%$, the asphaltenes were colloidally dispersed and were ultimately precipitated out of solution.

Therefore, at crude aromaticities lower than $20 \%$ toluene, some of the asphaltenes are certainly precipitated out of solution in the form of aggregates which are too large to adsorb and remain at the interface in order to affect the optimum degree of stabilization. In the middle range of crude aromaticity (30-60\% toluene, depending on sample), the asphaltenes are most likely near or right at the point of precipitating in the form of a fine dispersion ( i.e., very small particulates). This dispersion of fine asphaltene particulates is capable of adsorbing and stabilizing the water-oil interface to the optimum extent by forming a barrier which is mechanically resistant to the coalescence of the droplet phase. At the upper end of the aromaticity spectrum, the asphaltenes are colloidally, if not molecularly, dissolved in the oil phase and are more content to remain there in place of becoming interfacially active. Emulsions produced from highly aromatic crude mediums are less stable to the coalescence and phase separation of the dispersed water droplets.

It appears that as the system approaches 0.5 toluene volume fraction, the system begins to change from a colloidal system to a solution. The system begins to lose its stabilization properties as the surface active agents become weak. The amphoteric properties of the surface active agents gradually diminish and as such the oil and water moieties collapse causing the system to be converted to solution. As the system gradually changes to a solution from this point, its water retention capabilities gradually reduce because the system gradually becomes a homogeneous mixture brought about by the increased aromaticity of the solvent.

The result can also be interpreted in terms of asphaltene force profile. Since asphaltenes (amphiphilic) and heptane (apolar) are significantly different in molecular structure (highly aromatic of hetero-atoms vs aliphatic), the asphaltene molecules tend to self-associate, aggregate and precipitate in n-heptane. The dominant forces between asphaltenes in heptane arose from van der Waals forces. For toluene volume fraction $<0.2$, heptol is a poor solvent and there seem to be stronger adhesion between asphaltenes. While in a good solvent of pure toluene, the adhesion force will be almost zero. For heptol with toluene fraction 0.2 to 0.7 , the solvency of heptol gradually increased exhibiting relatively constant adhesion force. It appears that in poor solvents, asphaltenes-asphaltenes interactions are stronger than asphaltenes-heptol interactions, leading to stronger adhesion between asphaltene surfaces and hence increase in viscosity. Wang (2011) measured the adhesion force profile and reported that the force did not show highly significant change at toluene volume fraction of 0.4 to 0.6 in heptol as shown in figure 4.28. At this region, we observed high viscosity and less water separation for all the studied samples. This indicated the region of high emulsion stability due to the freed surface-active agent caused by the solvation with heptol.

Wang (2011) also showed that the interactions between asphaltene surfaces upon approach can be attractive or repulsive, depending on the quality of the solvent. The repulsive forces between asphaltenes in heptol of toluene volume fraction $>0.2$ are of steric nature and the electrical double layer force is negligible. The attractive force measured in heptane can be well fitted with only van der Waals forces. These observations indicate that heptol of toluene volume fraction $>0.2$ is a good solvent, whereas heptol of toluene volume fraction $<0.2$ is a poor solvent for asphaltenes. In good solvents, the immobilized asphaltenes repel each other due to steric repulsion caused by the swelling side-chains. In poor solvents, on the other hand, the immobilized asphaltenes attract to each other by van der Waals forces, leading to asphaltene aggregation and precipitation. In this study, the attraction between asphaltene surfaces was observed at toluene volume fraction above 0.2 , which does not mean that only at toluene volume fraction $<0.2$ can asphaltenes precipitate in heptol. At toluene volume fraction $<0.5$, the generally accepted heptol composition at which onset of asphaltenes was observed, it is possible that some asphaltene molecules in the asphaltene films are still in a "precipitated" or compact state, but there are still some asphaltene molecules in the asphaltene films soluble in heptol. The different studied samples show variations of asphaltenes solvation at this point. The later part of asphaltenes generates a repulsive force until at toluene volume fraction $<0.2$ the overall interactions between asphaltenes are attractive. 
Since attractive van der Waals forces are omnipresent in asphaltene/heptol system, it was interesting to investigate the variation of van der Waals forces with the solvent composition. This study indirectly investigated this force, as variation in viscosity of the emulsion since the solvation state of asphaltene was responsible for the varied viscosity of the emulsion. This study demonstrates a decrease in van der Waals attraction with increasing toluene volume fraction. The reduction of van der Waals forces with increasing toluene volume fraction contributes to reduced adhesion and hence less aggregation/flocculation of asphaltenes in toluene-rich heptol. However, the contribution of van der Waals forces to the total force when toluene volume fraction $>0.2$ is negligible. The dominant force between the asphaltene surfaces in heptol with toluene volume fraction $>0.2$ is steric repulsion. Moving towards poor solvent with decreasing toluene volume fraction in heptol, the solvent becomes less favorable for the stretching of asphaltene molecules. Parts of asphaltenes have aggregated with the polar segments shielded inside the aggregates. As a result, part of the asphaltene layer could be rigid and the others flexible. The rigid asphaltenes tend to condense to form a more compact layer. This might have been responsible for the reversal of the emulsion stability at toluene volume fraction of about 0.8 .

Using the scheme for dominant contributors to asphaltene solubility, state of aggregation, and the resulting impact on interfacial activity presented by McLean and Kilpatrick (1997) additional explanations can be offered to the results of this study. McLean and Kilpatrick scheme showed that as the volume fraction of the aromatic solvent increases, the bulky asphaltene precipitates that were very weakly solvated and hence provided very weak surfaceactive properties gradually become moderately solvated with better surface-active properties. The state of solvation increases as the aromaticity of the solvent increases until it becomes strongly solvated and the surface-active agent becomes weak again. Results of this work conformed to this scheme. Figures $1-5$ show that as toluene volume fraction increases, the stability of the emulsion increases with peak at about $0.4-0.5$ toluene volume fractions where the asphaltenes are moderately solvated. Above this region, the asphaltenes were strongly solvated and the surfaceactive agents become less active resulting in weak emulsion stability. High emulsion stability was however observed for Seplat-Oben emulsion at 0.7 toluene volume fraction as shown in figure 4 . This was due to the very high-water content of the emulsion. The shapes of the viscosity and percentage water resolved plots for the studied samples were also very informative. Figures 2, 3 and 4 for SPDC Otumara, Chevron VRMT and Seplat-Oben emulsions respectively informed a narrow range of stability compared to figures 1 and 5 for SPDC Yokri and Mobil QIT emulsions respectively. This implies that in controlling the solubility of asphaltenes in SPDC Otumara, Chevron VRMT and Seplat-Oben emulsions, we expect to have best demulsification outside a small range as shown in the figures. The other samples will be expected to be more problematic as the range of emulsion stability is wide. However, the respective figures provide the most precise point of solvent solvency for highest and least emulsion stability. Moreover, the scaling equations proved to be useful models for determination of emulsion stability as can be harvested from figures $1-5$.

The shape of figure 4 can be explained further in light of Bancroft's rule and Hydrophile-Lipophile Balance (HLB). Bancroft's rule states that the phase in which the surfactant is most soluble is the continuous phase of an emulsion and added that the solubility should be determined by the total surfactant concentration in a phase. In this study, asphaltene surfactant become more soluble as the aromaticity of the solvent increased implying that the surfactant concentration increased in the aqueous phase. An interesting case emerged for Seplat Oben sample. For this sample, the percentage water content was over $62 \%$ and the emulsion was within a phase inversion region. As the aromaticity of the solvent increased above 0.2 toluene fraction the asphaltene becomes more soluble and therefore increased the surfactant concentration. Anisa, Nour and Nour (2010) had mentioned that such increased in surfactant concentration can led to phase inversion. This is more likely in a system where other conditions like water cut level was also at point of phase inversion. Figure 4 therefore shows that at about 0.2 toluene fraction the Seplat Oben sample inverted from oil-in-water emulsion to water-in-oil emulsion.

Hydrophile-Lipophile Balance (HLB) is described by a number that gives an indication of the relative affinity of a surfactant molecule for the oil and aqueous phases of an emulsion. A molecule with a high HLB number has a high ratio of hydrophilic groups to lipophilic groups. According to Anisa, Nour and Nour (2010) changing the HLB of an emulsion, which depend on the nature and concentrations of the emulsifying agents can led to phase inversion. Michaels (2006) formulated the expression 
Correlation of Asphaltene Solvation with Stability of Crude Oil Emulsion Using Scaling Equations

HLB $=7+\sum$ (hydrophilic group numbers) $-\sum$ (lipophilic group numbers) Equation 19 .

Michael also added that the HLB range for water-in-oil and oil-in-water emulsions are $3-10$ and $11-18$ respectively. In this work, increasing the solvent aromaticity caused change in the HLB number. From Bancroft's rule, when more of the surfactant is soluble in the lipophilic phase, the number of lipophilic group increases and this result in reduction of HLB number according to Michaels' expression. For toluene volume fraction less than 0.2 for Seplat Oben sample, the number of lipophilic group might have increased as the aromaticity of the solvent increased and caused a phase inversion at about toluene volume fraction of 0.2 . As the emulsion becomes waterin-oil emulsion, the continuous phase of the emulsion becomes the hydrophilic phase and further increased in aromaticity caused increased in number of hydrophilic group. The result of this on Michaels' HLB expression is increase in HLB number. Figures $1-5$ show progressive impact of this increment as the toluene volume fraction increases.

\section{CONCLUSIONS}

The study shows that tuning the composition of heptol allows fine control of colloidal forces between asphaltene surfaces in an organic solvent and therefore determines the stability state of the emulsion. Statistically derived correlation equations provide for a range in the aromaticity of the crude medium for which an optimum stability is observed and therefore gives good understanding on the control of emulsion stability. The study further shows that emulsion inversion can be achieved by adjusting the concentration of surfactant. As the asphaltene surfactant become more soluble as the aromaticity of the solvent increased, the emulsion system of one of the samples was inverted because the surfactant concentration increased in the aqueous phase and these findings conformed to both HLB number theory and Bancroft's rule of emulsion.

\section{SOURCES OF FUNDING}

None.

\section{CONFLICT OF INTEREST}

None.

\section{ACKNOWLEDGMENT}

None.

\section{REFERENCES}

[1] Anisa, A. N. I; Nour, A. H.; Nour, Ashary H (2010): Castastrophic and Transitional Phase Inversion of waterin-oil Emulsion for Heavy and Light Crude Oil. Journal of Applied Sci., 10(23) 3076 - 3083.

[2] Cimino, R., et al. (1995): Solubility and Phase Behavior of Asphaltenes in Hydrocarbon Media, in Asphaltenes: Fundamentals and Applications, E.Y. Sheu and O.C. Mullins, Editors. 1995, Plenum Press: New York, 97-130.

[3] Ekott and Akpabio (2013): Understanding Asphaltene Solvation Nexus and Stability Analyses of Heavy Crude Oil Emulsions. Int. Journal of Engineering, Science and Technology. Vol.3, No. 1

[4] Espinat, D.; Ravey, J. C.; Guille, V.; Lambard, J.; Zemb, T. and Cotton, J. P. (1993): Colloidal macrostructure of crude oil studied by neutron and X-ray small angle scattering techniques. Journal de Physique IV, (Colloque C8, supplément au Journal de Physique I), 181-184.

[5] Hong, E. and Watkinson, P. (2004): A study of asphaltene: Solubility and Precipitation. Fuel, 83, 1881 - 1887. 
[6] Hu, Yu-Feng; Li, S; Liu, N; Chu, Y; Park, S. J.; Mansoori, G. A and Guo, T. (2004): Measurement and corresponding states modelling of asphaltene precipitation in Jilin reservoir oils. Journal of Petroleum Science and Engineering. 41(1-3), 199-221 - 242.

[7] McLean, J. D. and Kilpatrick, P. K. (1997): Effects of asphaltene aggregation in model heptane-toluene mixtures on stability of water-in-oil emulsions. Journal of Colloid and Interface Science, 196 (1), 23-34.

[8] Siffert, B.; Bourgeois, C. and Papirer, E. (1984): Structure and Water-Oil Emulsifying Properties of Asphaltenes. Fuel, 63 (6): p. 834-837.

[9] Spiecker, P. M. and Kilpatrick, P. K (2004): Interfacial Rheology of Petroleum Asphaltenes at the oil-water interface. Langmuir. 20. 4022-4032.

[10] Wang, S. (2011): Understanding Stability of Water-in-diluted Bitumen Emulsion by Colloidal Force Measurements. Ph.D. Thesis, University of Alberta, Edmonton. 